\title{
European space comes of age
}

The European Space Convention has now been formally signed, and the senior staff of the new European Space Agency appointed. Angela Croome reports on how things are now likely to shape up.

SPace collaboration was one of the first activities to bring together the countries of western Europe in a common enterprise which needed to reach a critical size that none of the partners could afford on their own. That was in the late 1950s, a long time ago. In the event, two organisations were set up, separating ends and means - the European Launcher Development Organisation (ELDO) and the European Space Research Organisation (ESRO); this was a bad beginning and a source of subsequent confusion and discord. There were always critics who urged that launching and experimentation should be kept together and that there should be a single organisation on the lines of NASA. And the mismatch in structure between the two organisations added strength to this argument. Eventually, the progressive escalation of cost and the regression in the practical value of the launcher element, together with rumblings over resignation from ELDO's initiating member, the UK, prompted the setting up in 1966 of a political council straddling both bodies (the European Space Conference (ESC) of ministers) and moves towards rationalisation and amalgamation. That was in 1966.

Rationalisation and amalgamation did not come until April 16, 1975 when the member countries gave political approval to the outstanding points of the European Space Convention, agreed in principle over a year before and formally signed at a meeting of plenipotentiaries in Paris last week. The delay of a year was caused both by having to wait for the outcome of France's review of her scientific spending and because of a lack of unanimity over the appointment of the new agency's director-general, which was linked to the disposal of other senior agency posts. Although the delay has not really mattered much in the long run the senior staff of ESRO, the caretaker body, have been grossly overworked and Europe's space plans have been made to look rather silly yet again. But ESRO can readily wear such nuisances. It has grown immeasurably in stature since the troubles of the mid-1960s, having pulled off several complex satellite projects and become

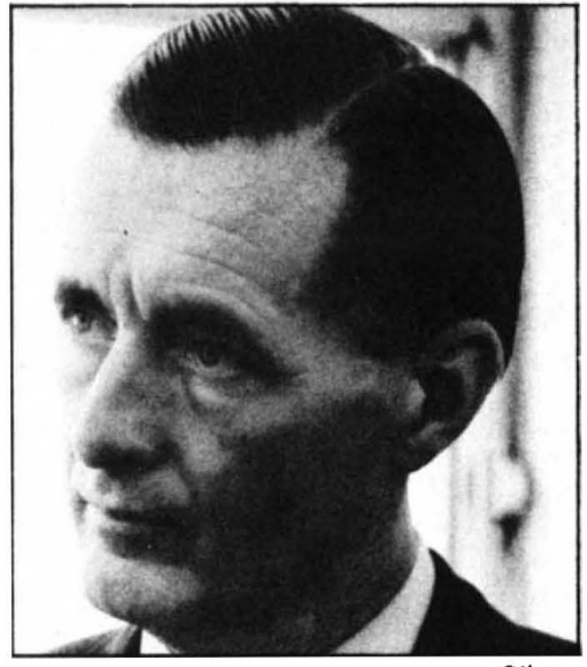

Gibson

an equal partner with the USA in a major applications project, the aeronautical satellite programme; it has also produced a convincing case for a key element in the forthcoming Spacelab-shuttle operation.

The new budget was adopted and a revised programme put in hand last year in spite of the lack of formal agreement on the convention and the appointment of the director-general. The basic difference between the old ESRO arrangement and the new European Space Agency (ESA) is sharply reflected in the budget; the agency's is to be six times as large as ESRO's was. European collaboration in space became almost overnight "a very different animal" in the words of ESRO's then acting director-general and head of administration, Roy Gibson. In 1973 the budget was 40 million Accounting Units, each unit being roughly equivalent to $\$ 1$ and in 1974 it was 240 MAU - so that from last summer (when ELDO had in reality already ceased to exist) ESRO, as ESA caretaker, was disposing of \$1 million every working day. The justification for these increased sums was the adoption of a substantial applications satellite programme. This has been the central plank of the new agency, and by relying for legality on the existing fully ratified ESRO convention it could get going ahead of the birth of the agency itself. It is expected that ratification of the ESA Convention by the 10 member states will take at least two years, during which time ESRO's convention will continue to be the legal base of the agency's activity under a 'gentleman's agreement'.

Roy Gibson was unanimously adopted as director-general by the ESRO Council in March, as were five new directors who now fill posts that had lain empty for the past year. Inevitably the atmosphere and performance of the new agency will owe much to its first director-general.

What sort of man is Roy Gibson and how does his administrative style compare with that of his two predecessors at ESRO? The first ESRO Director-General, Professor (now Sir) Hermann Bondi, who is at present Chief Scientific Adviser to the Ministry of Defence, may best be described as the ESRO magician. He inherited major crises-and proved a stunning negotiator by simply sweeping recalcitrant ministers, hesitant officials and critical journalists off their feet by his persuasive tongue and instant arguments. He foresaw that ESRO's success would depend on applications satellites and he promoted them tirelessly (especially his particular baby, the aeronautical satellite project), thereby largely oventurning ESRO's original remit, which rather puritanically restricted it to scientific research excluding the engineering aspects. $\mathrm{He}$ left ESRO healthy, even muscular, but a bit out of breath. The three years under the German scientific civil servant, $\mathrm{Dr}$ A. Hocker, was a complete contrast and perhaps gave the organisation the spell of quiet consolidation and development it needed after the Bondi whirlwind. Dr Hocker was so retiring that it was sometimes asked whether ESRO actually had a director-general. On the other hand he was scrupulously impartial and conscientious in the best civil service tradition. No national delegates were 'bamboozled', no 'deals' were made under the Hocker regime.

Roy Gibson has spent his working life (he is 50 ) in a variety of international administrative posts. $\mathrm{He}$ is no civil servant; he more resembles senior management in a multinational company. He is a glutton for work and long hours, and thrives on both. Pre-breakfast briefings and constant commuting by air are a regular pattern of his diary. He explains that the key to such a life is being able to drop off to sleep at any time-a talent he learned as a cipher officer in the Army during the Second World War. Another asset is his proficiency in several languages. As a Colonial officer in Malaya after the war he spoke Tamil; he subsequently picked up his French during 10 years of work on international safeguards for atomic energy with the UK Atomic Energy Authority and he speaks German at home with his half-Austrian half-Swedish wife.

What difference will the formal existence of the ESA make? Gibson puts 
first the fact that the agency is charged with rationalising the aerospace facilities of Europe and in particular "improving the world wide competitiveness of European industry"-in the words of the convention. An Industrial Policy Committee (IPC), which will take a long, hard look at the aerospace structure and performance of each member country, is already being formed. "It may need to tell some firms to drop cut" - in the transponder/repeater field, for example-should there prove to be a glut of manufacturers. The IPC will hold its first meeting this summer and by the end of the year there should be some answers.

The other aspect of rationalisation is the pooling of national space projects. Gibson is much encouraged by the change in attitude that was apparent at the meeting of European space ministers in April. Everybody expressed themselves keen to "play the card of Europe", in the French minister's words. Previously, member countries upheld national and European interests at the same time. "The ESA objectives cannot be brought off without sacrifice", says Gibson, "and up till now 'sacrifice' is something someone else makes." An early test may be whether the Germans are willing to pcol their direct-television broadcast satellite project.

Gibson is not a man for personal publicity though he seems to recognise the need for such an organisation as the ESA to have a face. He is rather clear on the management sityle that he intends to promote. He envisages a sharpening and streamlining of management responsibility, what he calls a much more integrated management approach. This can come about now that the full directorate (of nine) has been formed-five appointments had to await the decision on the director-general because of the distribution of jobs among member states. "People think it has all been cooked", says Gibson. "It has-but not in the sense that member countries have offloaded their duds on us. Today we have no 'diplomatic passengers'". His integrated management philosophy he describes as "simplicity born of desperation". He practises a "wide discussion" of any problem among the directors and all other staff involvedan entirely free debate where everyone chips in but once the executive decision is taken he requires complete loyalty of execution. "I expect whole-hearted acceptance even if $49 \%$ didn't want that direction beforehand." And if not, then they can go and peddle their matches somewhere else. He admits he feels "very strongly" about a "team approach" but not in terms of vagueness-the term team is often used to shift responsibility on to someone else.
"We simply cannot afford to be transformed into a woolly civil service-type outfit where people are carefully housed [for example] when they are not making a contribution."

How is any tendency of this kind to be prevented? To start with he considers work style of the ESRO-ESA type of operation is an asset. "In contrast to other organisations, for instance the OECD, there is a direct result-hardware." $\mathrm{He}$ explains that there is little paperwork involved and a rigid timetable. If things slip in preparing a space project everything goes awry. Consequently people at ESRO work very hard; they are enthusiasts and think nothing of working late into the night. "Most of our people are sold on space and the level of professional scrounging is extremely small." The way to keep things this way is above all to be extremely careful over recruiting. Gibson comments, however, that it is now eight years since people were recommended by member governments "to get them out of the way". The present standard of new staff is very high. The other aspect is tenure: "We need to steer a mid-course between security and bureaucracy". He sees the long-term contract as the key, and although the appointment of ESRO's director-generals was for three years, one senses that Gibson may be set for something more like a decade.

The stature of Europe-in-space is something that Gibson takes very seriously. He feels that the outside world does not appreciate Europe's capability. "No one doubts that Hughes, for instance, can do the whole thing" but it does not occur to them that western Europe as an entity can.

\section{ESA looks ahead}

IN a few weeks the first satellite under the European Space Agency's new name will be launched.

This year's satellite, COS-B, will carry a single large experiment, capable of detecting gamma rays with energies exceeding $20 \mathrm{MeV}$. The next scientific satellite planned for launch (in 1976) is GEOS, which will continue the theme of several European satellites in carrying out integrated studies of the magnetosphere. The earlier HEOS II satellite was the first to measure the magnetospheric properties of the polar cusp region, and also discovered the plasma mantle; HEOS I (now in its seventh year) continues to provide information about related phenomena.

But it is the other satellites in ESA's present programme which really point the way ahead for science in space. This path is very
The opportunity offered by the coincidence of the biennial Paris Air Show and the signing of the ESA Convention has not been missed, for example, and a three-day conference and demonstration of European capabilities has been put on for the benefit of key visitors, including some ministers. Non-ESRO projects such as Britain's defence communications link Skynet and the Franco-German regional satellite Symphonie as well as ground-stations were on view to show that Europe has the capability today to "do the whole thing". Part of this preoccupation is concerned with Spacelab, which Europe is building for the American Shuttle programme for the 1980 s and to which it will contribute half the first scientific payload. Gibson feels there is a danger of making propaganda over Europe's first entrance into manned spaceflight, as almost equal partners with the USA. Proper use of the possibilities Spacelab offers is much more important and he is not convinced that what this means is any better understood in the USA than in Europe. Spacelab experiments will cost less and the transfer from drawing board to flight fulfilment will be much quicker than the present seven years. They need not be miniaturised nor automatic. Integrating this highly complex programme is a daunting problem which Gibson has spent a lot of time thinking over. Financial, institutional and payload use, as well as development, all require to be effectively tried together.

The success of Spacelab would undoubtedly be the ultimate justification of the new agency - and the climax of Roy Gibson's career as director-general.

much one of collaboration. On the International Ultraviolet Explorer satellite, also due for launch in 1976 , ESA will be collaborating with both NASA and the United Kingdom (so the UK, as a member of ESA will be collaborating with itself!). This satellite should be accessible to any astronomer in much the same way that telescopes on Earth are used by many different members of the astronomical community.

More collaboration with NASA is involved in the International Sun Earth Explorer (ISEE) project, planned for 1977, which also follows the European tradition of investigating the interplanetary medium and Sun-Earth links. And ESA's biggest project, the Spacelab, ties the future of European space research even more closely to that of NASA; so the last satellite in the present programme, EXOSAT, is likely to be ESA's last independent scientific fling, for a good few years at least. 